\title{
Práticas alimentares de mulheres beneficiárias do Programa Bolsa Família na perspectiva da promoção da saúde
}

\section{Dietary practices of women beneficiaries of the Bolsa Familia program in the perspective of health promotion}

\author{
Vanessa Alves Ferreira \\ Universidade Federal dos Vales do Jequitinhonha e Mucuri. \\ Mestrado de Ensino em Saúde. Diamantina, MG, Brasil. \\ E-mail: vanessa.nutrøgmail.com \\ Rosana Magalhães \\ Fundação Oswaldo Cruz. Departamento de Ciências Sociais. Rio \\ de Janeiro, RJ, Brasil. \\ E-mail: rosanaळensp.fiocruz.br
}

\section{Resumo}

No Brasil, o diálogo entre o campo da nutrição e outras áreas de conhecimento, como as ciências humanas e sociais, tem contribuído para uma abordagem mais integradora e transdisciplinar, permitindo ricas análises acerca dos fenômenos sociais contemporâneos. Nesse debate, a promoção da saúde emerge como uma perspectiva instigante para os estudos acerca das práticas alimentares, os quais propõem dimensões importantes em suas análises, tais como o fortalecimento da autonomia dos sujeitos, o autocuidado e também a valorização das experiências subjetivas e do contexto sociocultural em que os indivíduos estão inseridos. Nesse sentido, o objetivo deste estudo foi investigar as práticas alimentares de mulheres pobres e obesas, dentro da perspectiva de promoção da saúde, a partir da valorização do espaço social. Para tanto, foram realizadas 24 entrevistas em profundidade e trinta em grupos focais com titulares do Bolsa Família, programa governamental de transferência condicionada de renda. Na metodologia, utilizouse o instrumental qualitativo, a fim de melhor compreender as percepções, interpretações e práticas em torno da alimentação do grupo. Os resultados revelaram componentes fundamentais ao desenho de intervenções públicas voltadas à promoção de práticas alimentares saudáveis para a população pobre do país.

Palavras-chave: Promoção da Saúde; Obesidade; Segurança Alimentar e Nutricional; Comportamento Alimentar. 


\section{Introdução}

In Brazil, the dialogue between the nutrition field and other areas of knowledge, such as Human and Social Sciences, has contributed to a more integrative and transdisciplinary approach, allowing rich analyses of contemporary social phenomena. In this debate, health promotion emerges as an instigating perspective for studies about eating practices, which propose important dimensions in their analysis, such as strengthening the autonomy of the subjects, selfcare, and the valuing of subjective experiences and the sociocultural context in which individuals are inserted. In this sense, the objective of this study was to investigate the dietary practices of poor and obese women, within the perspective of health promotion, based on the appreciation of the social space. To that end, 24 in-depth interviews and 30 focus groups were held with beneficiaries of the Bolsa Família program. In the methodology, qualitative instruments were used to better understand the perceptions, interpretations and practices related to the feeding of this group. The results showed fundamental components to be observed in the design of public interventions aimed at promoting healthy eating practices among the poor in the country.

Keywords: Health promotion; Obesity; Food and nutrition security; Feeding behavior.
No Brasil, as iniciativas de diálogo entre o campo da alimentação e nutrição e outras áreas de conhecimento têm sido intensificadas nos últimos anos (Canesqui; Garcia, 2005; Castro, 2015; Contreras; Gracia, 2011). De maneira geral, essas pesquisas e reflexões buscam elucidar a dinâmica das práticas alimentares dos sujeitos sociais a partir de uma abordagem multidimensional. Tais investigações têm contribuído para uma perspectiva mais integradora e transdisciplinar na área da nutrição, fazendo emergir um amplo campo científico de análise a partir da convergência de conhecimentos. Neste artigo corroboramos o debate, e acreditamos ser fundamental incorporar "novos olhares" nas investigações de fenômenos sociais contemporâneos, como a comensalidade urbana, a gastronomia, os sistemas agroalimentares, as práticas em torno da alimentação e do corpo, a obesidade, as doenças não transmissíveis e o estilo de vida (Ferreira, 2014).

Sob esse prisma, a promoção da saúde emerge como uma perspectiva promissora para investigações e estudos no campo da alimentação e nutrição na contemporaneidade (Brasil, 2012; Ferreira; Magalhães, 2007; WHO, 2017). De acordo com uma vertente de estudiosos, a promoção da saúde se apresenta como um caminho metodológico instigante ao propor dimensões importantes para análise, que incluem: o fortalecimento da autonomia dos sujeitos; o autocuidado; a mobilização social; o engajamento de diferentes setores e atores sociais, assim como a valorização das experiências subjetivas e do contexto sociocultural em que os indivíduos estão inseridos, visando promover qualidade de vida (Delormier; Frohlich; Potvin, 2009; Macdonald; Veen; Tones, 1996; Poland; Krupa; McCall, 2009).

A noção de qualidade de vida parte do pressuposto de que é uma representação social criada a partir de parâmetros subjetivos, incluindo bem-estar, felicidade, realização pessoal, entre outros, e também preceitos objetivos, cujas referências são a satisfação das necessidades básicas de indivíduos e populações. Qualidade de 
vida é, portanto, uma dimensão eminentemente humana, que diz respeito ao grau de satisfação encontrado nas esferas da vida familiar, amorosa, social e ambiental. Pode ser considerada uma síntese cultural de todos os elementos que um sujeito entende como seu padrão de conforto e bem-estar. 0 termo abrange muitos significados que são expressos por intermédio de práticas, conhecimentos, experiências e valores dos indivíduos em diferentes espaços, sendo, desse modo, uma construção social com a marca da relatividade cultural (Minayo; Hartz; Buss, 200o).

A nosso ver, estudos que se propõem a compreender as práticas e vivências dos sujeitos em seus espaços de interação social são importantes para que se possa apreender as diferentes concepções a respeito da categoria qualidade de vida, para além do discurso biomédico e/ou midiático que tende a estreitar esse conceito vinculando-o, em geral, a preceitos normativos e generalizantes. Assim, este estudo objetivou investigar as práticas alimentares de um grupo de mulheres pobres e obesas, titulares do programa Bolsa Família (BF), dentro da perspectiva da promoção da saúde.

\section{Metodologia}

O estudo realizou-se com mulheres beneficiárias do BF que apresentavam diagnóstico de obesidade e eram moradoras de áreas urbanas e rurais da cidade histórica de Diamantina, Minas Gerais, Brasil. A cidade se localiza na região noroeste do estado de Minas Gerais, a aproximadamente trezentos quilômetros da capital Belo Horizonte. De acordo com os dados provenientes do Instituto Brasileiro de Geografia e Estatística para o ano de 2016, o município possui uma população adstrita de mais de 48 mil habitantes (IBGE, 2016). Diamantina se caracterizou como a maior produtora de pedras preciosas e de ouro do século XVIII e pertence ao Circuito do Diamante e da Estrada Real. Atualmente, a exuberância histórica, artística e cultural da cidade é preservada e revalorizada por intermédio do título de Patrimônio Cultural da Humanidade, concedido pela Unesco no ano de 1997. A cidade de Diamantina se insere ainda na região do Vale do Jequitinhonha, considerada uma das áreas de maior desigualdade social do país. Dados do Instituto de Pesquisa Econômica e Aplicada confirmam a espacialização da pobreza na região. A existência de indivíduos vivendo em condições de pobreza e indigência atingiu o índice de 30\%, considerado um dos mais elevados do país, semelhante apenas às regiões do Norte e Nordeste (Silveira et al., 2007).

A pesquisa foi desenvolvida no período de 2013 a 2014 e buscou uma aproximação com o contexto de vida de mulheres titulares do programa social BF, a fim de compreender a dinâmica que permeava a alimentação e o perfil de obesidade do grupo. Os critérios de seleção das mulheres incluíram: (1) cadastro em uma Estratégia de Saúde da Família (ESF) local; (2) cadastro no BF; e (3) diagnóstico da obesidade a partir do parâmetro do Índice de Massa Corporal (IMC $30 \mathrm{~kg} / \mathrm{m}^{2}$ ) proposto pela Organização Mundial de Saúde (WHO, 20oo). Foi utilizada ainda uma cesta de indicadores sociais para classificar as mulheres enquanto pobres, incluindo dados sobre cor/raça, chefia do lar, tamanho das famílias, número de filhos, condições de moradia, acesso a bens e serviços, condições de trabalho, entre outros. Todas essas informações combinadas permitiram selecionar famílias socialmente vulneráveis, utilizando critérios para além da dimensão puramente normativa, com a incorporação de indicadores sociais e econômicos relacionados às condições gerais de vida e de bemestar do grupo (Sen, 2001; Tilly, 2006; Townsend, 1993).

A respeito do BF podemos dizer que faz parte de uma política social mais ampla, implementada no Brasil desde o ano de 2003 durante o governo Lula. Previsto na Lei Federal $n^{0} 10.836$, de 9 de janeiro de 2004 (Brasil, 2004), o BF é um programa que visa contribuir para o combate à pobreza e às desigualdades sociais no Brasil a partir de três eixos principais de atuação: (1) complementação da renda (garante o alívio mais imediato da pobreza); (2) acesso a direitos sociais através das condicionalidades nos setores da educação, saúde e assistência social; e (3) articulação com várias políticas sociais a fim de estimular o desenvolvimento das famílias, contribuindo 
para que superem a situação de pobreza. 0 programa visa, a curto prazo, aliviar os problemas advindos da pobreza e a longo prazo, investir no capital humano, evitando a permanência no ciclo intergeracional da pobreza.

$\mathrm{O}$ instrumento para coleta de dados seguiu um roteiro previamente estabelecido que foi testado durante a fase do pré-campo. O questionário continha informações socioeconômicas sobre consumo e práticas alimentares, atividades de trabalho e lazer, obesidade e aspectos relacionados ao programa BF. No tratamento dos dados utilizouse a análise de conteúdo proposta por Bardin (2011). Os dados foram compilados em cinco eixos temáticos: (1) práticas alimentares; (2) corpo; (3) programa BF; (4) atividades laborais e de lazer; (5) condições de vida. A escolha pela técnica de análise do conteúdo deveu-se a seu largo emprego no âmbito da pesquisa social por permitir apreender os sentidos atribuídos pelos sujeitos às práticas e experiências nos espaços da vida cotidiana (Bardin, 2011). A análise de conteúdo apresenta como orientação epistemológica a fenomenologia e a compreensão. Trata-se de um estudo de natureza subjetiva, descritiva e indutiva, pautado na compreensão de que a realidade é complexa, processual e dinâmica.

Nesse aspecto, a pesquisa qualitativa se alinha à perspectiva da promoção da saúde no que diz respeito às noções de qualidade de vida, bem-estar e saúde pautadas na visão holística dos sujeitos sociais (Delormier; Frohlich; Potvin, 2009; Ferreira, 2014). Esse enfoque multidimensional, dialógico, processual e relacional proposto pela abordagem da promoção da saúde visou fundamentalmente suplantar visões estanques nos estudos sobre as práticas alimentares. Soma-se a essa questão o fato de que a perspectiva da promoção da saúde se apoia em estudos que valorizam, sobretudo, o contexto em que os sujeitos vivem, trabalham e interagem socialmente. Esse ponto de vista reflete, em parte, o reconhecimento de que a maior parte das práticas em saúde é orientada pelo contexto social. Além disso, procura ampliar cada vez mais o estudo das redes sociotécnicas e dos espaços de interação social para subsidiar o planejamento, a implementação e a avaliação das iniciativas no setor. Tais análises podem, segundo alguns autores, criar valiosas oportunidades para o fortalecimento das ações de promoção da saúde na atualidade, especialmente para o enfrentamento de fenômenos sociais contemporâneos, incluindo as mudanças recentes nos padrões alimentares das populações (Macdonald; Veen; Tones, 1996; Poland; Krupa; McCall, 2009).

Torna-se oportuno destacar que serão analisados os resultados parciais da pesquisa, tendo em vista que o objetivo deste artigo é analisar particularmente as práticas alimentares do grupo. Importante salientar também que o estudo cumpriu os princípios éticos contidos na Declaração de Helsinki da Associação Médica Mundial (1964) no que diz respeito ao sigilo dos informantes e ao livre acesso às informações. Foram apresentados Termos de Consentimento Livre e Esclarecido e prestaram-se explicações adicionais em todas as etapas da pesquisa (Schnaider, 2008). Além disso, as mulheres receberam acompanhamento na Atenção Primária de Saúde local. A pesquisa foi aprovada pelo Comitê de Ética em Pesquisa da Plataforma Brasil do Ministério da Saúde sob o número de registro: 05882512300005240.

\section{Resultados e discussão}

No que diz respeito ao nosso universo de pesquisa, foram entrevistadas 24 mulheres em seus domicílios e trinta nos grupos focais. A wwmédia de idade do grupo foi de 48 anos. Na análise dos indicadores sociais combinados observou-se que a migração fez parte das histórias de vida das participantes. Essa é uma característica dos pobres no Brasil. Em geral, a perda dos vínculos pessoais diminui oportunidades de trabalho e condição salarial, fragilizando a rede de proteção social desses segmentos (Marques, 2010; Sen, 2001).

As mulheres apresentavam ainda um baixo nível educacional, fundamental incompleto, e algumas foram consideradas analfabetas funcionais. Estavam inseridas em ocupações de pouco prestígio, exercendo atividades de diarista, doméstica, babá, artesã, entre outras. A vulnerabilidade à pobreza era agravada pelo estabelecimento de redes sociais menores, locais e menos variadas, 
do tipo "primárias", ou seja, bastante restritas ao próprio núcleo familiar. Essa é uma característica marcante das redes sociais dos mais pobres (Marques, 2010). A desqualificação das ocupações exercidas por essas mulheres se refletia em baixos rendimentos: a média salarial encontrada foi de um a dois salários-mínimos mensais.

Quanto aos arranjos familiares, podemos caracterizá-los como do tipo "casal com filhos" e "monoparentais", ou seja, aqueles chefiados por mulheres, sem cônjuges e com filhos. De acordo com os dados do Censo 2010 (IBGE, 2010b), essa é uma das novas tendências nas dinâmicas familiares brasileiras. A chefia feminina é uma situação vivenciada por mulheres pertencentes a diferentes classes sociais. No entanto, é uma dinâmica preocupante para os setores mais empobrecidos da população, por participarem menos do mercado de trabalho e terem baixos rendimentos. De fato, as estatísticas oficiais apontam que há uma posição desigual na renda familiar dos domicílios monoparentais (IBGE, 2015). Importante destacar que nesta pesquisa se verificou uma maior precariedade nas condições gerais de vida nos arranjos domiciliares cuja chefia era feminina (Ferreira, 2014).

\section{Sentidos e significados das práticas alimentares}

Neste estudo, observamos que a alimentação do grupo era atravessada pelas singularidades e especificidades do contexto local. Constatamos que as mulheres estabeleciam estratégias de consumo alimentar que incluíam a predileção por um cardápio monótono, composto por alimentos calóricos à base de farinhas, açúcares e gorduras. Esse padrão tem sido uma tendência nos grupos de baixa renda, conforme revelam outros estudos (Canesqui, 1976; Canesqui, Garcia, 2005; Ferreira; Magalhães, 2005; Ibase, 2008). A seleção de gêneros densos, com alto poder de saciedade, era compreendida pela ameaça de fome e escassez que é permanente nesses segmentos. Mas não apenas isso. Para além dos aspectos materiais de vida, os elementos de natureza simbólico-cultural operavam nessas escolhas alimentares, de tal forma que era frequente o consumo de alimentos próprios da cultura local, tais como: angu, couve, carne de porco, frango refogado, quiabo, abóbora, verduras silvestres (mostarda, rúcula, almeirão), biscoito de polvilho, torresmo e garapa (caldo da cana-deaçúcar). Esse consumo alimentar evidenciava, em certa medida, a dimensão da influência exercida pelo tradicionalismo cultural sobre as escolhas e preferências alimentares do grupo. Os mesmos alimentos apareceram com frequência ao lado de produtos processados e ultraprocessados, entre eles, café, açúcar, pão, bolo industrializado, arroz, feijão, óleo de soja e macarrão. Em geral, esses alimentos foram associados pelo grupo à conveniência, praticidade, palatabilidade e saciedade. De fato, os alimentos ultraprocessados estão cada vez mais presentes no cardápio da população pobre, não apenas no Brasil, mas também em outros países latino-americanos. Um reflexo da expansão cada vez mais incisiva das corporações transnacionais de alimentos que têm controlado boa parte dos sistemas alimentares contemporâneos (Monteiro et al., 2013).

Conforme revelam estudos recentes, essa tendência tem repercutido negativamente na saúde das populações. A maioria dos itens citados possui pouca qualidade nutricional e, em contrapartida, elevadas quantidades de gorduras, açúcares, sódio, aditivos e realçadores de sabor (Katz; Meller, 2014). Soma-se à questão a desestruturação das culturas e tradições locais. Esse fenômeno tem preocupado enormemente os organismos internacionais que preconizam uma agenda emergencial para o controle do problema (Paho, 2015).

Com relação às preparações culinárias presentes na dieta das mulheres, verificamos o consumo do "mexido" na refeição do jantar na área urbana, uma prática comum e historicamente construída no estado de Minas Gerais. Segundo Abdala (1997), faz parte da "lógica da economia nos tempos difíceis", quando se aproveitava tudo, incluindo as sobras dos alimentos. Já as mulheres da área rural consumiam preparações à base de milho, como o "ensuado" e a "tiborna”. O primeiro consistia de uma mistura de farinha de milho com sal e óleo, que se levava ao fogo brando. A segunda era uma preparação feita com farinha de milho, açúcar e café.

Tais misturas podem ser consideradas “multisseculares" porque são típicas da cultura alimentar do país. De acordo com Frieiro (1982), 
muitas dessas preparações foram descritas no período colonial pelos "naturalistas europeus", entre elas, a pipoca, o curau, a pamonha, o cuscuz e a canjica. Segundo o autor, os escravos eram alimentados com angu durante o dia e com feijão à noite. Posteriormente, a dieta dos tropeiros (homens que conduziam tropas de mulas e percorriam o interior do Brasil transportando todo o tipo de mercadorias) também era pouco variada. Consistia de feijão, farinha de mandioca, toucinho, carne seca, couve e café, de onde surgiu o termo "feijão do tropeiro", preparação feita com a mistura de alguns desses ingredientes. A base da alimentação do "roceiro pobre", por sua vez, era semelhante: feijão com angu. Assim, o paladar para o consumo dessas preparações se relaciona fortemente a preferências, gostos e costumes próprios da cultura alimentar brasileira (Frieiro, 1982).

O almoço foi considerado a principal refeição para o grupo pesquisado. Assim, alimentos consumidos em outras ocasiões do dia eram desprestigiados e, por essa razão, apareciam sempre no diminutivo: "de manhã eu tomo um cafezinho". A "merenda" (como as mulheres se referiam ao lanche da tarde) pareceu ser uma prática pouco comum. Entretanto, é interessante observar que foi justamente nesse período do dia que as mulheres disseram cometer os "excessos" alimentares, conforme os relatos: "abro a geladeira toda hora"; "é a hora que eu belisco". Já a refeição do jantar parece pouco a pouco perder o valor entre as famílias, sendo, muitas vezes, substituída por um "lanchinho", "mexidinho", "macarrãozinho". Essa é uma tendência observada mais recentemente nas famílias brasileiras (Canesqui; Garcia, 2005).

O consumo de alimentos proteicos, especialmente o leite, o queijo, a carne de boi e o pescado foi raramente citado. Da mesma forma, o consumo de frutas revelou ser praticamente nulo; quando elas apareciam no cardápio das famílias, eram oferecidas exclusivamente aos filhos. Essa prática evidenciou que as mulheres negligenciam seu próprio consumo de alimentos em favor dos filhos, netos e/ou do marido (Aguirré, 200o). Tal situação foi mencionada com frequência pelas entrevistadas: "sempre tem que ter uma verdura para os meninos e um macarrão para o meu marido"; "quando eu penso em comida não penso em mim, eu penso é nos meus filhos; “de manhã eu tomo café com garapa. Aí eu passo o dia inteiro. Agora os meninos eu faço comida pra eles". A esse respeito, não tem sido incomum constatar o baixo consumo de frutas por parte da população brasileira. Pesquisas nacionais (IBGE, 2010a, 2011) revelam que esse perfil de consumo acarreta deficiências nutricionais. Interessante destacar, ainda, que, segundo Frieiro (1982), o mesmo cenário foi descrito na literatura desde a época colonial.

No que diz respeito ao consumo intrafamiliar de alimentos observamos que, de maneira geral, nas famílias existia uma rotina compartilhada para a realização das refeições, comportamento que reforça, em certa medida, o estereótipo da "família tradicional mineira", muito religiosa, cujas refeições assumem o lugar do sagrado, devendo ser compartilhadas por todos, em espírito de comunhão. Com efeito, "faz parte do universo das representações do mineiro o fato de conferir grande valor à família e às relações de parentesco" (Dutra, 1991, p. 114). A antropóloga Mary Douglas (1974) descreveu a dimensão eminentemente social da refeição. De acordo com a autora, para cada refeição há um horário, uma disposição à mesa, um tipo de combinação de alimentos, um ritual, uma conduta social. Nesse sentido, o "comer junto", com a "família unida", se reveste de significados simbólicos. Envolve, portanto, um conjunto de dimensões, como intimidade, convivência, reunião do grupo doméstico, sociabilidade, comunicação e conflitos no universo familiar. Opostamente, as refeições "fora de casa", no espaço da "rua", eram escassas no grupo pesquisado. Esse comportamento parece envolver duas dimensões. A primeira diz respeito ao consumo de alimentos "fora de casa”, que aparenta ser uma ação mais comum em outros grupos e contextos sociais (IBGE, 2010a). A segunda compreende o lugar simbólico assumido pela "comida" na realidade das famílias mineiras: o da intimidade e da família (Dutra, 1991). Para Woortmann (1986), a alimentação expõe a intimidade e também o status social, por revelar aquilo que se come, sendo para alguns grupos uma prática muito particular, restrita ao espaço da casa e da família. 
Ainda com relação ao consumo de alimentos, embora tenha sido unânime o discurso de que "todos comem a mesma coisa", foi possível constatar uma polaridade entre o corpo obeso das mulheres e o corpo aparentemente desnutrido dos homens. Esse fenômeno nos pareceu intrigante. Entretanto, os discursos permitiram verificar uma problemática muito presente nesses arranjos: o alcoolismo masculino. De acordo com Frieiro (1982), o álcool sempre foi um refúgio para todos os males, sobretudo para o homem pobre, servindo ainda como poderoso estimulante, fonte de energia. Não raro, as mulheres mencionaram o uso frequente de álcool por seus companheiros e todos os conflitos vivenciados pela família em função dessa dependência.

Além das estratégias de consumo alimentar verificadas entre as famílias, foi possível observar também estratégias para aquisição e compra de alimentos. Em geral, as entrevistadas selecionavam os itens considerados prioritários, de maior "necessidade" e "mais baratos". Notou-se em muitas situações que a escolha alimentar era pautada nas "necessidades" da família, de acordo com o que o "dinheiro permitia comprar". Nesse contexto, verificamos ser menor a margem para escolhas alimentares nos segmentos estudados (Canesqui, 1976; Ferreira; Magalhães, 2005; Ferreira et al., 2010; Ibase, 2008).

De fato, na análise de todo o material empírico verificou-se a relação entre alimentação e status social. Notadamente, tanto as mulheres da área urbana quanto as da área rural revelaram dificuldades materiais para a compra e consumo de alimentos no dia a dia, o que ficou evidente em vários depoimentos: "a gente vê e não pode comprar"; "está tudo muito caro e não dá pra ficar comprando"; "comer bem é uma coisa que a gente não tem. Que não pode ter. Se eu for comprar verdura, o arroz com feijão, como é que fica? A gente não tem dinheiro pra comprar fruta". Essa tem sido uma evidência nos estudos acerca do consumo alimentar de famílias beneficiárias do BF (Ibase, 2008).

Em geral, a compra de mantimentos era realizada mensalmente pelas famílias em supermercados de maior porte, localizados na área urbana da cidade, ou em pequenos armazéns (onde podem comprar “fiado" por receberem o benefício do BF). No caso das famílias do meio rural, a compra de alimentos era dificultada pela escassa na oferta de serviços. No que se refere aos gastos com alimentação, o custo no orçamento doméstico era de duzentos a quatrocentos reais mensais, conforme verificado em outros trabalhos (Ferreira; Magalhães, 2005; Ferreira et al., 2010).

As singularidades assumidas pelas práticas alimentares das famílias parecem, de fato, percorrer os séculos, caminhando, em certa medida, na contramão da dinâmica de homogeneização da alimentação contemporânea. Essa constatação é um achado, tendo em vista o fenômeno mundial de "aculturação alimentar" fruto das profundas transformações advindas do processo de globalização, e nos leva a crer que, ainda que "novos" alimentos sejam incorporados à dieta do grupo, predominará no cardápio das famílias a apreciação de alimentos tradicionais da cultura mineira. Especialmente, no meio rural, onde o consumo de preparações a base de milho ainda se faz muito presente. A esse respeito, Contreras e Gracia (2011, p. 391) sinalizam que "a "história da alimentação humana apresenta, paradoxalmente, conservadorismos duráveis e transformações profundas".

O padrão alimentar das mulheres encontrava-se fundamentalmente vinculado a hábitos, costumes e práticas nutricionais historicamente construídos, evidenciando, portanto, a forte influência da dimensão cultural nas escolhas e preferências do grupo. Igualmente, expressava os lugares sociais, a dinâmica das relações, as mudanças e transformações impostas pela vida contemporânea, assim como reforçava a identidade e o status social do grupo.

Em paralelo, ao mesmo tempo que as mulheres preservavam a cultura e a tradição, incorporavam novas preferências e gostos alimentares em seus cardápios. Nesse sentido, "novos" alimentos, como macarrão, açúcar refinado, biscoitos industrializados e óleo de soja, foram incluídos no cardápio diário das famílias, ao lado do consumo tradicional de café, garapa, milho (em suas variações), carne de porco e de frango, verduras silvestres e do mexido. A agregação desses "novos" 
alimentos se deve à ampliação e massificação de alguns gêneros, em decorrência do barateamento no custo e também das ações persuasivas de marketing direcionadas a esses grupos. Tais gêneros se tornam, portanto, boas opções por se enquadrarem nas condições materiais do grupo, atendendo à praticidade imposta pela vida moderna, ao paladar e à saciedade (Canesqui, 1976; Canesqui, Garcia, 2005; Contreras; Gracia, 2011; Ferreira et al., 2010; Ibase, 2008).

\section{Por um fio: a fragilidade da rede de proteção social}

Neste estudo evidenciamos uma segunda categoria a ser analisada: as condições de vida e pobreza do grupo. Sem dúvida, as faces mais dramáticas das iniquidades sociais nessas famílias foram as condições de moradia e infraestrutura local. Assim, ainda que a maior parte das residências fosse assistida pela rede geral de água e energia elétrica, nem todas tinham acesso a saneamento e coleta de lixo. Observou-se também a ausência ou deficiência de transporte público. Além disso, nos bairros e distritos havia pouca oferta de produtos, serviços e espaços de lazer. No contexto urbano era comum o convívio com a criminalidade e a violência. No meio rural as condições locais revelaram-se extremamente precárias: estradas de terra com muitos buracos, sem iluminação e sinalização. A poeira e o clima seco ainda geravam um enorme desconforto. Em dias de chuva, as estradas ficavam interditadas. Esse contexto ocasionava um isolamento social considerável no grupo, acentuando as condições de desigualdade das famílias.

Soma-se a esse cenário de adversidades a rotina extenuante de afazeres vivida pelas mulheres, que assumiam majoritariamente os serviços domésticos, os cuidados com filhos, netos e outros familiares, e no caso das "chefes de famílias", também o sustento da casa. Como titulares do BF, gerenciavam o escasso recurso do benefício e respondiam pelo cumprimento das condicionalidades (levar os filhos para vacinação, consultas médicas e pesagens periódicas nos serviços de saúde). As mulheres realizavam ainda um deslocamento intenso no trajeto "casa-trabalho", sobretudo a pé. Tamanho acúmulo de funções se refletia nos "raros" momentos destinados ao descanso e ao lazer: "não tenho tempo pra nada". Nesses raros momentos, foi possível identificar que “assistir televisão" parece a modalidade recreativa mais comumente utilizada pelo grupo, por ser uma forma econômica, segura e disponível. Além disso, segundo Matta (1997, p. 73), "tudo o que remete ao uso, cuidado e recuperação do corpo, e que como consequência implica descanso e renovação está ligado ao mundo doméstico e íntimo da casa”.

Essa difícil realidade vivenciada pelas mulheres desencadeava sintomas clínicos, que foram autorreferidos com frequência pelo grupo, como "nervoso", "estresse", “ansiedade" e "depressão". Tais sintomas foram considerados pelas mulheres os principais responsáveis por transgressões e excessos alimentares: "eu como muito porque eu sou nervosa"; "como porque sou muito ansiosa"; "toda hora eu como porque tenho depressão". De acordo com Novaes (2010), os indivíduos pobres e obesos são, em geral, sujeitos poliqueixosos que, via de regra, se descrevem como pessoas extremamente ansiosas e com bastante labilidade afetiva. Ou seja, alternam sintomas de ansiedade com depressão e melancolia.

As mulheres entrevistadas vivenciavam, dessa maneira, faces contraditórias da exclusão e da pobreza local, as quais se expressavam ora na escassez de condições materiais e sociais de vida, ora na opulência do corpo. Os corpos retratavam, de alguma maneira, as situações penosas do viver no contexto local. Para além do corpo biológico e da fome fisiológica, parecia existir um corpo que demandava, mas não se saciava (Seixas, 2009; Sudo; Luz, 2010). As transgressões na esfera alimentar nos pareceram, em certa medida, uma demanda por dimensões mais amplas relacionadas à cidadania, como direitos civis, trabalho, renda, visibilidade social, equidade na divisão dos papéis de gênero, educação, saúde e, sobretudo, a própria sobrevivência existencial (Rego; Panzini, 2013). A "visibilidade corporal" advinda da obesidade parecia contrapor-se à "invisibilidade social" vivida pelas mulheres. Diferentemente da pobreza, que não era reconhecida socialmente, o corpo gordo parecia querer ser notado, ou seja, querer de fato existir. 
Nesse cenário, as especificidades do contexto local impressas no perfil de corpo obeso e nas práticas alimentares das entrevistadas parecem escapar dos padrões da boa alimentação e do corpo magro.

Assim, a estratégia metodológica de promoção da saúde revelou-se uma escolha acertada por permitir desnudar os saberes e as práticas das mulheres em seus contextos de interação social, utilizando o instrumental qualitativo. Nesse grupo de mulheres emergia um estilo de vida com contornos próprios, distinto dos observados em outros grupos sociais. Entre elas parece vigorar a predileção por alimentos regionais, a realização das refeições no espaço da casa, a valorização do convívio familiar, bem como das tradições e da cultura local. O perfil de atividade física, por sua vez, mostrou ser intenso, com um deslocamento considerável no trajeto casa-trabalho acompanhado da dupla jornada laboral. O lazer para as mulheres relacionava-se ao descanso, a atividades manuais e ao convívio com filhos e/ou netos.

As evidências empíricas aqui expostas apontam para a necessidade de uma reflexão profunda por parte dos profissionais de saúde que exercem atividades com tais indivíduos e coletividades. É preciso ainda um maior investimento intelectual na realização de estudos com essa abordagem compreensiva. Em geral, os estudos sobre obesidade desvinculam as práticas alimentares do contexto social, desvalorizando aspectos importantes que operam nessa dinâmica tão complexa e processual (Ferreira, 2014). A reflexividade e o empoderamento social e cultural podem ser um caminho mais promissor para o enfrentamento do excesso de peso nesses grupos.

\section{O papel do programa Bolsa Família nas práticas alimentares do grupo}

O terceiro eixo de análise recai sobre o papel do BF nas práticas alimentares da população pesquisada. Dessa forma, verificou-se que o programa assumia um lugar fundamental na alimentação das famílias por amenizar, em algum grau, situações extremas de privação. Para algumas entrevistadas o benefício representava o "fio que sustentava suas famílias", impedindo que elas vivenciassem situações de desfiliação e precariedade. Particularmente, o programa assumia um papel decisivo nas práticas alimentares do grupo, já que era predominantemente gasto com a compra de alimentos (Ibase, 2008; Rego; Panzini, 2013).

De fato, os resultados sobre o uso do benefício têm demonstrado o impacto positivo do BF sobre o consumo de alimentos no âmbito familiar (Duarte; Sampaio; Sampaio, 2009; Ibase, 2008; Rego; Panzini, 2013). Mudanças favoráveis foram observadas no aumento dos gastos com alimentação, no maior número de refeições realizadas pelas famílias e no incremento da variedade de gêneros consumidos. Contudo, muitas famílias ainda se encontram em situação de insegurança alimentar e nutricional, revelando que a cidadania nesse quesito ainda não foi garantida para todos. Por outro lado, nota-se o consumo de alimentos calóricos e pouco nutritivos, o que tem contribuído para agravar o excesso de peso nesses segmentos.

Portanto, muitos são os desafios impostos ao programa. Além de sua abrangência e do impacto que gera no orçamento da União, o maior impasse tem sido a superação da pobreza e das inequidades. Considerando que tanto a pobreza como as desigualdades sociais são fenômenos históricos e multidimensionais persistentes no país, creditar em apenas um programa social a superação dessas inequidades seria uma visão bastante simplista do problema (Bichir, 2010). Nesse sentido, observamos que o BF se revelou uma intervenção política insuficiente para abrir "portas de saída da pobreza" e promover, consequentemente, a inclusão social das mulheres pobres. Ou seja, o programa não pareceu capaz de transformar o contexto de extrema precariedade em que viviam essas famílias.

Reconhecemos que, apesar de todos os avanços obtidos com o BF ao longo dos anos, ainda existe um hiato social que requer ampla intervenção do Estado. Por essa razão, um escopo de políticas públicas integradas parece ser uma medida política mais consistente a fim de superar o histórico déficit social e econômico da região estudada. Há que se garantir, para além dos programas sociais de combate à fome e à pobreza, políticas amplas, de natureza intersetorial, que considerem as necessidades dessas mulheres e de suas famílias. 


\section{Alimentação \& promoção da saúde: um diálogo possivel}

Por fim, os resultados desta pesquisa reforçam o argumento inicial a respeito da importância de valorizar o espaço social nos estudos das práticas alimentares dentro do campo da alimentação e nutrição (Canesqui; Garcia, 2005; Contreras; Gracia, 2011). Dessa maneira, este estudo revela a presença de tradições e conservadorismos interagindo com "novidades" no padrão alimentar das entrevistadas, o que se mostra na incorporação de produtos industrializados largamente difundidos entre os pobres. Tais evidências nos levam a crer que as recentes mudanças nos padrões alimentares da população brasileira podem apresentar contornos e perfis distintos em diferentes territórios e contextos sociais.

A nosso ver, esse percurso metodológico possibilitou novos olhares para o fenômeno, que podem ser úteis para repensar as ações governamentais de enfrentamento do problema. Os programas de distribuição de renda, tal como o BF, são capazes de contribuir para práticas alimentares saudáveis em populações de baixa renda, quando combinados com outras medidas que integrem um escopo mais amplo de ações intersetoriais (Castro, 2015; Cotta; Machado, 2013). Iniciativas que promovam o desenvolvimento dos sistemas agroecológicos em nível local, a fim de ampliar o acesso, a disponibilidade e o consumo de alimentos saudáveis, valorizando a cultura local, devem ser incentivadas. A garantia dos direitos sociais alinhada à implementação de políticas públicas saudáveis deve ser fomentada para que esses grupos tenham condições sociais que promovam a qualidade de vida, objetivo maior da promoção da saúde.

\section{Considerações finais}

Este trabalho permitiu compreender a dinâmica das interações sociais que permeia as práticas alimentares de mulheres pobres, obesas e titulares do BF, reconhecendo a importância de considerar as especificidades dos espaços de vida individual e coletiva para entender as práticas alimentares dos sujeitos. A nosso ver, as pesquisas que se propõem a incorporar abordagens teórico-metodológica mais compreensivas e relacionais, utilizando a perspectiva da promoção da saúde, são fundamentais para subsidiar ações de enfrentamento da obesidade entre mulheres pobres. Tais abordagens devem propor análises dialógicas e integradoras acerca do tema, a fim de superar visões rígidas e estáticas. Neste debate, a perspectiva da promoção da saúde assume relevância por enfatizar o território, a rede de relações sociais, as condições de vida, trabalho e lazer, bem como a cultura e as tradições locais.

Portanto, compreender as dinâmicas socioeconômicas e culturais desses espaços revelase imprescindível para desnudar a complexa rede que atravessa as práticas alimentares dos sujeitos. Só assim nos parece possível propor ações mais resolutivas de controle do excesso de peso entre os pobres. Acreditamos que este estudo possa estimular novas pesquisas e contribuir para o debate acerca da alimentação, obesidade e promoção da saúde entre pobres no país.

\section{Referências}

ABDALA, M. C. Receita de mineiridade: a cozinha e a construção da imagem do mineiro. Uberlândia: Edufu, 1997.p. 188.

AGUIRRÉ, P. Aspectos socioantropológicos de la obesidad en la pobreza. In: PEÑA, M.; BACALLAO, J. (Org.). La obesidad en la pobreza: un nuevo reto para la salud pública. Washington, DC: Opas, 200o. p. 13-25.

BARDIN, L. Análise de conteúdo. Lisboa: Edições 7O, 2011.

BICHIR, R. M. O Bolsa Família na berlinda? Os desafios atuais dos programas de transferência de renda. Novos Estudos, São Paulo, n. 87, p. 115129, 2010.

BRASIL. Ministério do Desenvolvimento Social e Combate à Fome. Programa Bolsa Família: legislação e instruções. [201-]. Disponível em: <https://goo.gl/k2iFoV>. Acesso em: 5 ago. 2016.

BRASIL. Lei no 10.836 , de 9 de janeiro de 2004. Cria o Programa Bolsa Família e dá outras 
providências. Diário Oficial da União, Brasília, DF, 12 jan. 2004. Seção 1, p. 3-7.

BRASIL. Ministério do Desenvolvimento Social e Combate à Fome. Marco de referência de educação alimentar e nutricional para as políticas públicas. Brasília, DF, 2012.

CANESQUI, A. M. Comida de pobre, comida de rico: um estudo sobre alimentação num bairro popular. 1976. Tese (Doutorado em Ciências) Departamento de Medicina Preventiva e Social, Universidade Estadual de Campinas, Campinas, 1976.

CANESQUI, A. M.; GARCIA, R. W. D. (Org.). Antropologia e nutrição: um diálogo possível. Rio de Janeiro: Fiocruz, 2005.

CASTRO, I. R. R. Challenges and perspectives for the promotion of adequate and healthy food in Brazil. Cadernos de Saúde Pública, Rio de Janeiro, v. 31, n. 1, p. 7-9, 2015.

CONTRERAS, J.; GRACIA, M. Alimentação, sociedade e cultura. Rio de Janeiro: Fiocruz, 2011.

COTTA, R. M. M.; MACHADO, J. C. Programa Bolsa Família e segurança alimentar e nutricional no Brasil: revisão crítica da literatura. Revista Panamericana de Salud Pública, Viçosa, v. 33, n. 1, p. 54-6o, 2013.

DELORMIER, T.; FROHLICH, K. L.; POTVIN, L. Food and eating as social practice: understanding eating patterns as social phenomena and implications for public health. Sociology of Health \& Illness, Henley on Thames, United Kingdom, v. 31, n. 2, p. 215-228, 2009.

DOUGLAS, M. Natural symbols: explorations in cosmology. Nova Iorque: Pantheon, 1974.

DUARTE, G. B.; SAMPAIO, B.; SAMPAIO, Y. Programa Bolsa Família: impacto das transferências sobre os gastos com alimentos em famílias rurais. Revista de Economia e Sociologia Rural, Brasília, DF, v. 47, n. 4, p. 903-918, 2009. DUTRA, R. C. A. A boa mesa mineira: um estudo de cozinha e identidade. 1991. Dissertação (Mestrado em Antropologia Social) - Museu
Nacional, Universidade Federal do Rio de Janeiro, Rio de Janeiro, 1991.

FERREIRA, V. A. Desigualdades sociais, pobreza e obesidade. 2014. Tese (Doutorado em Saúde Pública) - Escola Nacional de Saúde Pública Sergio Arouca da Fiocruz, Rio de Janeiro, 2014. FERREIRA, V. A.; MAGALHÃES, R. Obesidade e pobreza: o aparente paradoxo: um estudo com as mulheres da Favela da Rocinha, Rio de Janeiro, Brasil. Cadernos de Saúde Pública, Rio de Janeiro, v. 21, n. 6, p. 1792-180o, 2005.

FERREIRA, V. A.; MAGALHÃES, R. Nutrição e promoção da saúde: perspectivas atuais. Cadernos de Saúde Pública, Rio de Janeiro, v. 23, n. 7, p. 1674-1681, 2007.

FERREIRA, V. A. et al. Desigualdade, pobreza e obesidade. Ciência \& Saúde Coletiva, Rio de Janeiro, v. 15, p. 1423-1432, 2010. Suplemento 1.

FRIEIRO, E. Feijão, angu e couve: ensaio sobre a comida dos mineiros. Belo Horizonte: Itatiaia, 1982.

IBASE - INSTITUTO BRASILEIRO DE ANÁLISES SOCIAIS E ECONÔMICAS. Repercussões do programa Bolsa Família na segurança alimentar e nutricional das famílias beneficiadas. Rio de Janeiro: Ibase, 2008.

IBGE - INSTITUTO BRASILEIRO DE GEOGRAFIA E ESTATÍSTICA. Pesquisa de orçamentos familiares 2008-2009: antropometria e estado nutricional de crianças, adolescentes e adultos no Brasil. Rio de Janeiro: IBGE, 2010a.

IBGE - INSTITUTO BRASILEIRO DE GEOGRAFIA E ESTATÍSTICA. Censo 201o. Rio de Janeiro: 2010b. Disponível em: <https://censo2o1o.ibge. gov.br/>. Acesso em: 8 dez. 2017.

IBGE - INSTITUTO BRASILEIRO DE GEOGRAFIA E ESTATÍSTICA. Cidades. Disponível em: <https://cidades.ibge.gov.br/>. Acesso em: 5 fev. 2016.

IBGE - INSTITUTO BRASILEIRO DE GEOGRAFIA E ESTATÍSTICA. Pesquisa de orçamentos familiares 2008-2009: análise do consumo 
alimentar pessoal no Brasil. Rio de Janeiro:

IBGE, 2011.

IBGE - INSTITUTO BRASILEIRO DE GEOGRAFIA E ESTATÍSTICA. Pesquisa mensal de emprego.

Brasília. 2015. Disponível em: <www.ibge.gov.br>. Acesso em: 5 fev. 2015.

KATZ, D. L.; MELLER, S. Can we say what diet is best for health? Annual Review of Public Health, Palo Alto, v. 35, p. 83-103, mar. 2014.

MACDONALD, B.; VEEN, C.; TONES, K. Evidence for success in health promotion: suggestions for improvement. Health Education Research, Oxford, v. 11, n. 3, p. 367-376, 1996.

MARQUES, E. Redes sociais, segregação e pobreza em São Paulo. São Paulo: Unesp, 2010.

MATTA, R. A casa \& a rua: espaço, cidadania, mulher e morte no Brasil. Rio de Janeiro: Rocco, 1997.

MINAYO, M. C. S.; HARTZ, Z. M. A.; BUSS, P. Qualidade de vida e saúde: um debate necessário. Ciência \& Saúde Coletiva, Rio de Janeiro, v. 5, n. 1, p. 7-18, 2000.

MONTEIRO, C. A. et al. Ultra-processed products are becoming dominant in the global food system. Obesity Reviews, Oxford, v. 14, p. 21-28, nov. 2013. Suplemento 2.

NOVAES, J. V. Com que corpo eu vou? Sociabilidade e usos do corpo nas mulheres das camadas altas e populares. Rio de Janeiro: PUC-RJ: Pallas, 2010.

PAHO - PAN AMERICAN HEALTH

ORGANIZATION. Ultra-processed food and drink products in Latin America: trends, impact on obesity, policy implications. Washington, DC: Paho, 2015.

POLAND, B.; KRUPA, G.; MCCALL, D. Settings for health promotion: an analytic framework to guide intervention design and implementation. Health Promotion Practice, Thousand Oaks, v. 10, n. 4, p. 505-516, 2009.

REGO, W. L.; PANZINI, A. Vozes do Bolsa Família: autonomia, dinheiro e cidadania. São Paulo: Editora Unesp, 2013.
SCHNAIDER, T. B. Ética e pesquisa. Acta Cirúrgica Brasileira, São Paulo, v. 23, n. 1, p. 107-111, 2008.

SEIXAS, C. M. Comer, demandar e desejar: considerações psicanalíticas sobre o corpo e o objeto na obesidade. 2009. Dissertação (Mestrado em Saúde Coletiva) - Instituto de Medicina Social da Universidade do Estado do Rio de Janeiro, Rio de Janeiro, 2009.

SEN, A. Desigualdade reexaminada. Rio de Janeiro: Record, 2001.

SILVEIRA, F. G. et al. Dimensão, magnitude e localização das populações pobres no Brasil. Brasília, DF: Ipea, 2007.

SUDO, N.; LUZ, M. T. Sentidos e significados do corpo: uma breve contribuição ao tema. Ceres, Rio de Janeiro, v. 5, n. 2, p. 101-112, 2010.

TILLY, C. O acesso desigual ao conhecimento científico. Tempo Social, São Paulo, v. 18, n. 2, p. 47-63, 2006.

TOWNSEND, P. The international analysis of poverty. New York: Harvester Wheatshef, 1993.

WHO - WORLD HEALTH ORGANIZATION. Obesity: preventing and managing the global epidemic. Geneva: WHO, 2000.

WHO - WORLD HEALTH ORGANIZATION. Global strategy on diet, physical activity and health.

Geneva: WHO, 2004. Disponível em: <https://goo. gl/UAMng5>. Acesso em: 28 nov. 2017.

WHO - WORLD HEALTH ORGANIZATION. Global Health Observatory (GHO). 2017. Disponível em: <https://goo.gl/AiGrcn>. Acesso em: 28 nov. 2017.

WOORTMANN, K. A. Comida, a família e a construção do gênero feminino. Revista de Ciências Sociais, Rio de Janeiro, v. 29, n. 1, p. 103-129, 1986.

\section{Contribuição dos autores}

Ferreira foi responsável pela elaboração, redação e revisão do artigo. Magalhães participou da orientação da pesquisa, elaboração $e$ revisão do artigo.

Recebido: 24/04/2017

Reapresentado: 07/11/2017

Aprovado: $16 / 11 / 2017$ 